\title{
Pulsed-laser-induced nc-Si and $\mathrm{nc}-\mathrm{Si} / \mathrm{SiO}_{x}$ core-shell structures on Si substrates
}

\author{
Y. Ma \\ Division of Physics and Applied Physics, School of Physical and Mathematical Sciences, Nanyang \\ Technological University, Singapore 637371 \\ X.T. Zeng \\ Surface Technology Group (STG), Singapore Institute of Manufacturing Technology, \\ Singapore 638075 \\ T. Yu, Y. Zhu, and Z.X. Shen ${ }^{\text {a) }}$ \\ Division of Physics and Applied Physics, School of Physical and Mathematical Sciences, Nanyang \\ Technological University, Singapore 637371
}

(Received 20 October 2007; accepted 3 January 2008)

\begin{abstract}
Pulsed-laser-induced Si nanostructures on Si substrates were investigated using third harmonic $\mathrm{Nd}^{3+}$ :yttrium aluminum garnet $(355 \mathrm{~nm})$ laser irradiation under ambient conditions. Nanostructures were found in the laser-irradiated areas as well as in their surrounding areas. The laser-irradiated areas contained Si nanoparticles with an average size of about $50 \mathrm{~nm}$. In the vicinity of the laser-irradiated areas, uniform $\mathrm{nc}-\mathrm{Si} / \mathrm{SiO}_{x}$ core-shell structures were observed. Scanning electron microscopy images indicate that the core-shell structures had an average size of $500 \mathrm{~nm}$ while Raman data show that the $\mathrm{Si}$ cores were made of a large number of much smaller Si nanocrystals (nc-Si). The photoluminescence (PL) measurement of $\mathrm{nc}-\mathrm{Si} / \mathrm{SiO}{ }_{x}$ core-shells exhibited a broad visible emission centered at $640 \mathrm{~nm}$, which can be assigned as due to defects at the interface between $\mathrm{nc}-\mathrm{Si}$ and $\mathrm{SiO}_{x}$ as well as oxygen-related defects.
\end{abstract}

\section{INTRODUCTION}

Laser-induced periodic surface structures (LIPSS) such as ripples, ridges, and cones resulting from lasermaterial interaction have stimulated considerable efforts in the area of laser microprocessing for microelectronics applications. ${ }^{1-5}$ A variety of morphologies on a solid surface have been extensively reported by adjusting the laser fluence, wavelength, pulse duration, ambient gas species, and processing pressure ${ }^{6-12}$ or with the aid of prepatterned structure. ${ }^{5,13}$ The surface microstructure and nanostructure of laser-induced $\mathrm{Si}$, the semiconductor industrial mainstay, have significant impact on the application of miniaturized Si-based devices. ${ }^{14,15}$

Since the discovery of efficient visible photoluminescence (PL) from porous $\mathrm{Si}$ (PSi), nanocrystal $\mathrm{Si}$ (nc-Si) and the $\mathrm{nc}-\mathrm{Si} / \mathrm{SiO}_{x}$ system have been gaining widespread interest due to their potential application as light-emitting devices fully compatible with Si-based optoelectronic integrated circuits. ${ }^{16-21}$ Quantum confinement and oxygen related defects have been proposed as the origins of intense visible PL in these low-dimensional $\mathrm{Si}$ struc-

\footnotetext{
a) Address all correspondence to this author.

e-mail: zexiang@ntu.edu.sg

DOI: $10.1557 / J M R .2008 .0118$
}

tures. ${ }^{22-28}$ However, the mechanism of the PL is still an open question.

In this paper, we report the simultaneous formation of $\mathrm{Si}$ nanostructures and nc-Si capped by $\mathrm{SiO}_{x}$ core-shell structures by using $\mathrm{Nd}^{3+}$ :yttrium aluminum garnet (YAG) third-harmonic generation $(355 \mathrm{~nm})$ laser irradiation. It is noted that $\mathrm{nc}-\mathrm{Si} / \mathrm{SiO}_{2}$ system has its own importance in the semiconductor industry because $\mathrm{SiO}_{2}$ surface is a well-established material known to passivate $\mathrm{Si}$ surfaces where the $\mathrm{Si} / \mathrm{SiO}_{2}$ system is fully compatible with Si technology.

\section{EXPERIMENTAL}

Si (100) oriented wafers were loaded onto the target holder of a pulsed laser deposition (PLD) chamber after ultrasonic cleaning in acetone and subsequent rinsing in deionized water. A focused $\mathrm{Nd}^{3+}$ :YAG laser with a focal spot of $1 \mathrm{~mm}$ in diameter was used as the light source to impinge on the samples. The laser beam has a wavelength of $355 \mathrm{~nm}$, a laser fluence of $20 \mathrm{~mJ} / \mathrm{mm}^{2}$, a pulse duration of $30 \mathrm{~ns}$, and a repetition rate of $10 \mathrm{~Hz}$. The experiments were carried out under ambient environment. Postannealing of the laser-treated samples was performed in a tube furnace in air.

The sample morphologies after laser irradiation were 
studied by field emission scanning electron microscopy (FE-SEM; JEOL, Tokyo, Japan, JSM-6700F). Energy dispersive x-ray diffraction (EDX) was used to investigate the composition variations before and after annealing. Raman spectroscopy (Witech, Germany, CRM200; $\lambda_{\text {laser }}=532 \mathrm{~nm}$ ) and photoluminescence spectroscopy were performed to study the crystallinity, size distribution in $\mathrm{nc}-\mathrm{Si} / \mathrm{SiO}_{x}$ system, and light-emitting properties.

\section{RESULTS AND DISCUSSION}

After Nd:YAG laser irradiation, Si nanoparticles were produced at the laser-irradiated area, as shown in Fig. 1(a). The average size of the nanoparticles is about $50 \mathrm{~nm}$. Figure 1(b) shows the scanning electron microscope (SEM) image of Si nanoparticles after annealing at $900{ }^{\circ} \mathrm{C}$ for $2 \mathrm{~h}$ in air. Obviously, after the thermal treatment, the nanoparticles grew bigger, to an average size of $80 \mathrm{~nm}$. Typical ripple structures were observed in the laser-irradiated areas at lower magnification SEM image. After annealing, the Si nanoparticles in some areas of the ripples disappear due to the aggregation of grown particles, as seen from Fig. 1(c). EDX measurement shows a variation of atomic ratio between $\mathrm{Si}$ and $\mathrm{O}$ before and after annealing. The content of $\mathrm{O}$ atomic percentage increases from $7 \%$ to $50 \%$ after annealing, which indicates the Si nanoparticle surface is oxidized and passivated by a thin layer of $\mathrm{SiO}_{x}(x<2)$, while the particles grow in size.

An interesting observation of the laser ablation is the formation of much larger particles (about $500 \mathrm{~nm}$ ) in the vicinity of the laser-irradiated area, as seen from Fig. 2(a). These half-micron-sized particles are the result of bombarded-out $\mathrm{Si}$ atoms from the laser-irradiated area and are uniformly distributed on the $\mathrm{Si}$ substrate. The inset in Fig. 2(a) is the high-magnification image. However, the SEM images after annealing shown in Fig. 2(b) imply one particle in Fig. 2(a) may contain a large number of ultrafine particles as the cluster-like morphology presents after annealing. To gain a better understanding of such particles, Raman spectroscopic measurement $(\lambda=532 \mathrm{~nm})$ was performed. Figure 3 shows the Raman spectra before and after annealing. The Raman peak of bulk-Si transverse optical (TO) mode is located at $520 \mathrm{~cm}^{-1}$ with full width at half-maximum (FWHM) of $7 \mathrm{~cm}^{-1}$. The half-micron-sized particles before annealing shown in Fig. 2(a) present a red-shifted and asymmetric Raman peak, which can be fitted by two Gaussian peaks positioned at $495 \mathrm{~cm}^{-1}$ with FWHM of $34 \mathrm{~cm}^{-1}$ and $516 \mathrm{~cm}^{-1}$ with FWHM of $11 \mathrm{~cm}^{-1}$. According to Refs. $22,24,27$, and 29, the broad low-energy band centered at $495 \mathrm{~cm}^{-1}$ results from a disordered Si structure while the narrow high energy band centered at $516 \mathrm{~cm}^{-1}$ results from Si nanocrystals of average size $4 \mathrm{~nm}$. This result indicates that the half-micron-sized particle is made up of

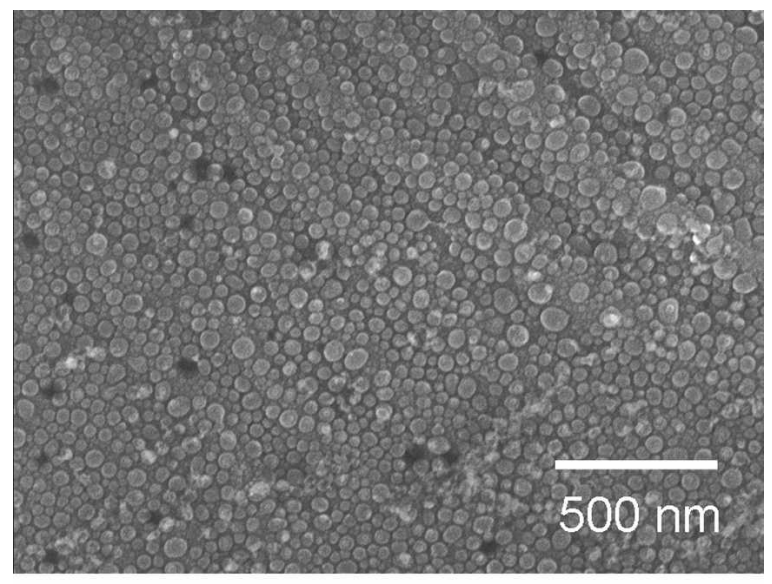

(a)

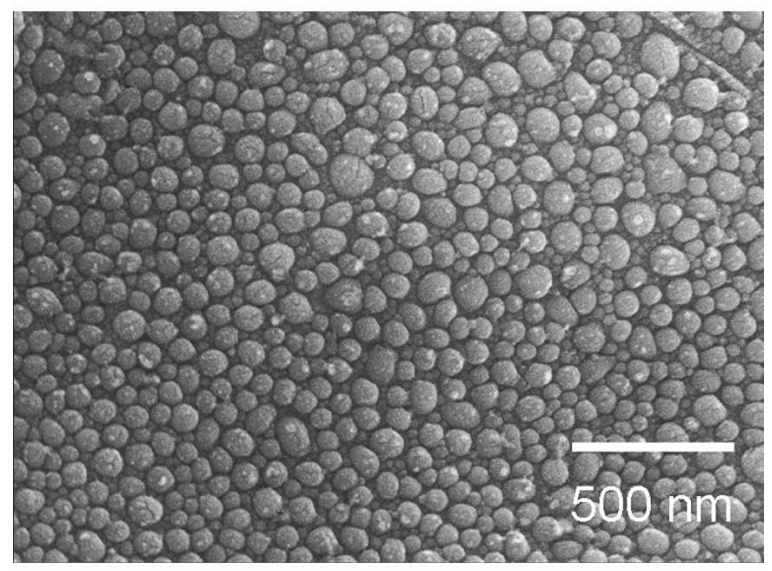

(b)

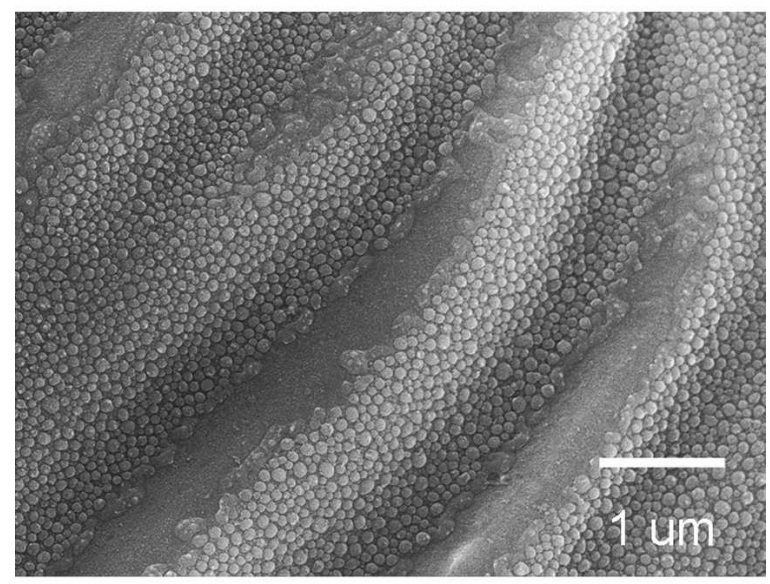

(c)

FIG. 1. SEM images of laser-irradiated area: (a) before annealing $\mathrm{Si}$ nanoparticles with average size of $50 \mathrm{~nm}$, (b) after annealing Si nanoparticles with average size of $80 \mathrm{~nm}$, and (c) after annealing, some Si nanoparticles have disappeared at the laser-induced ripple structure.

a large amount of nc-Si. After annealing, the nc-Si Raman peak is shifted to $517 \mathrm{~cm}^{-1}$, and its FWHM becomes narrower than that before annealing. This result suggests the nc-Si grows bigger after annealing. Hence, annealing 


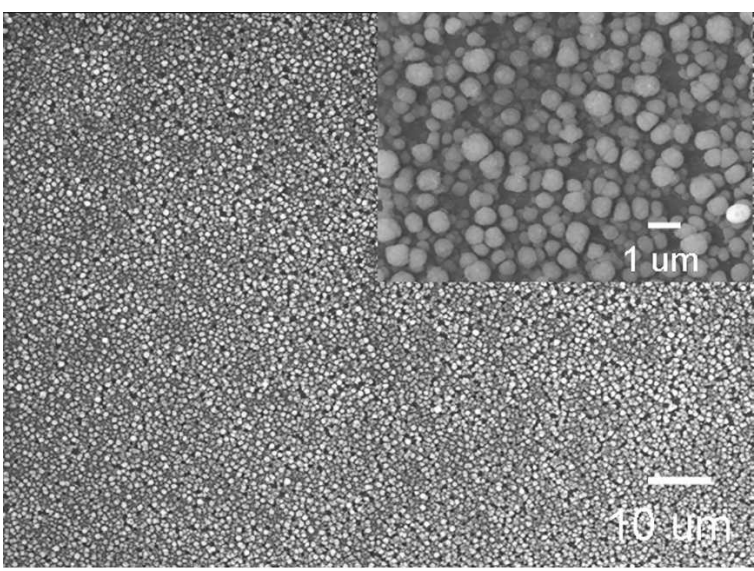

(a)

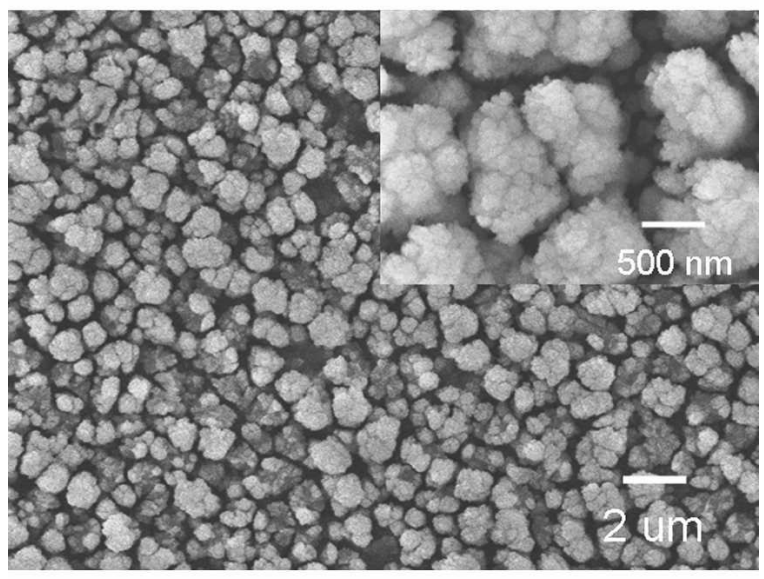

(b)

FIG. 2. SEM images of bombarded-out Si particles in the vicinity of laser-irradiated area: (a) before annealing and (b) after annealing. The insets are the high magnification images.

increases the thickness of the $\mathrm{SiO}_{x}$ layer as well as the average size of the nc-Si cores.

Figure 4 shows the room-temperature PL band of the samples before and after annealing. The broad PL peak centered at $640 \mathrm{~nm}$ was observed before annealing. The PL spectrum has been reported to be very sensitive to the surface chemistry of $\mathrm{Si}$ nanocrystals, the interface between nc-Si and $\mathrm{SiO}_{x}$, and oxygen-related defects. ${ }^{21,23,25}$ Because the experiments were carried out in ambient environment, the bombarded-out Si particles may be oxidized and form the nc-Si core capped with a thin layer of substoichiometric $\mathrm{SiO}_{x}$ structure. The exciton localized at the interface between the core nc-Si and shell $\mathrm{SiO}_{x}$ as well as the oxygen vacancies are considered the main sources of the observed emission in our samples. After annealing, the PL peak is shifted from $640 \mathrm{~nm}$ (red) to $760 \mathrm{~nm}$ (infrared) and becomes 10 times stronger than that before annealing (see Fig. 4). This may be due to the larger size of the nc-Si core after annealing. As evidenced by EDX investigation, $\mathrm{O}$ content increases

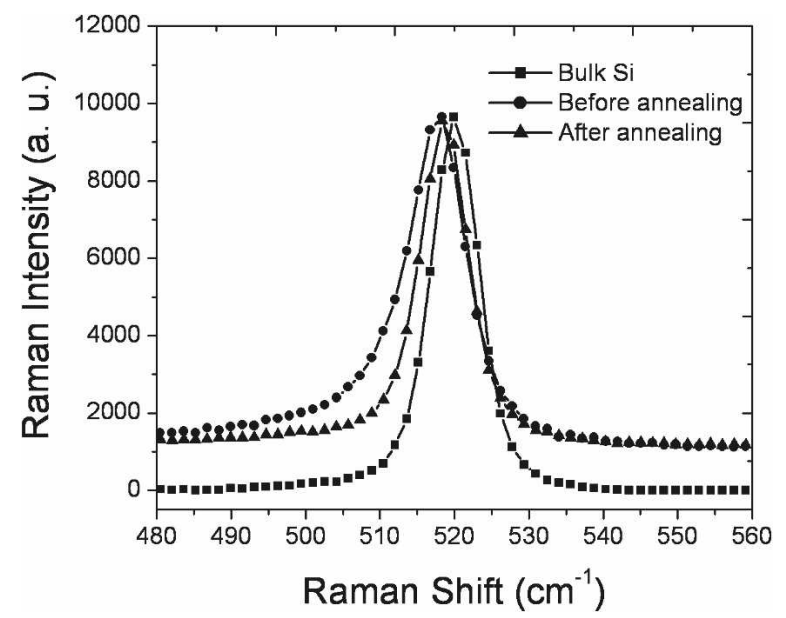

FIG. 3. Raman spectra of the bombarded-out particles before and after annealing.

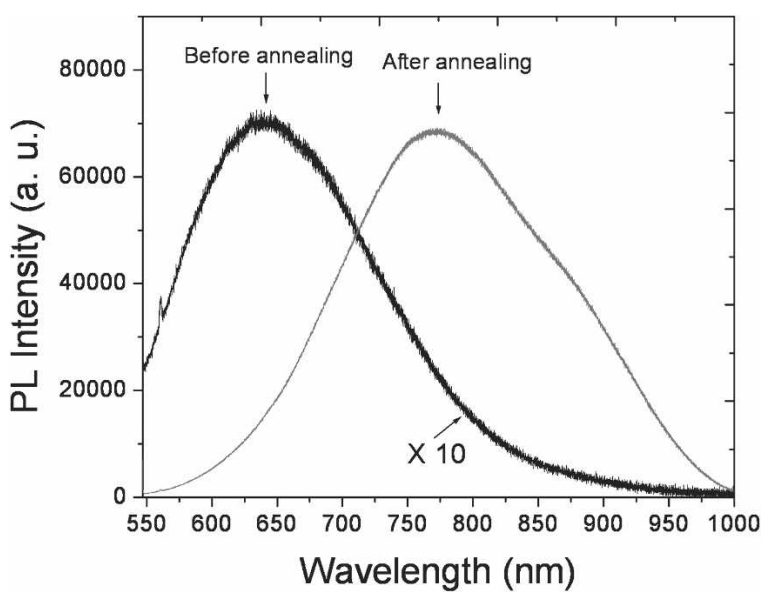

FIG. 4. PL spectra of bombarded-out particles before and after annealing.

after annealing, which means the change of nc-Si surface property may also lead to the shift of the PL band.

\section{CONCLUSION}

We have demonstrated the formation of Si nanostructure and $\mathrm{nc}-\mathrm{Si} / \mathrm{SiO}_{x}$ core-shell structure using third harmonic $\mathrm{Nd}^{3+}$ :YAG $(355 \mathrm{~nm})$ laser irradiation under ambient conditions. The nanoparticles formed in the laser irradiated area have an average size of $50 \mathrm{~nm}$. After annealing, the nanoparticles have grown bigger to an average size of $80 \mathrm{~nm}$. In the vicinity of the laser spot, half-micron-sized particles were observed, consisting of 4-nm nc-Si/SiO ${ }_{x}$ core-shell structures as evidenced by Raman data. The PL measurements exhibited a broad visible emission centered at $640 \mathrm{~nm}$, which can be attributed to the defect-related PL peak, i.e., the interface between $\mathrm{nc}-\mathrm{Si}$ and $\mathrm{SiO}_{x}$, as well as oxygen-related defects. 


\section{REFERENCES}

1. A.V. Demchuk and V.A. Labunov: Surface morphology and structure modification of silicon layer radiation. Appl. Surf. Sci. 86, 353 (1995).

2. J.J. Dubowski, A. Compaan, and M. Prasad: Laser assisted dry etching ablation of InP. Appl. Surf. Sci. 86, 548 (1995).

3. Y.F. Lu, W.K. Choi, Y. Aoyagi, A. Knomura, and K. Fujii: Controllable laser-induced periodic structures at silicon-dioxide/ silicon interface by excimer laser irradiation. J.Appl. Phys. $\mathbf{8 0}$. 7052 (1996).

4. Y.F. Lu, J.J. Yu, and W.K. Choi: Theoretical analysis of laserinduced periodic structures at silicon-dioxide/silicon and silicondioxide/aluminum interface. Appl. Phvs. Lett. 71, 3439 (1997).

5. X.Y. Chen, Y.F. Lu, B.J. Cho, Y.P. Zeng, J.N. Zeng, and Y.H. Wu: Pattern-induced ripple structures at silicon-oxide/silicon interface by excimer laser irradiation. Appl. Phvs. Lett. 81, 1344 (2002).

6. J.F. Young, J.E. Sipe, J.S. Preston, and H.M. van Driel: Laserinduced periodic surface damage and radiation remnants. Appl. Phvs. Lett. 41, 261 (1982).

7. J.E. Sipe, J.F. Young, J.S. Preston, and H.M. van Driel: Laserinduced periodic surface structure. I. Theory. Phys. Rev. B 27. 1141 (1983).

8. J.F. Young, J.S. Preston, H.M. van Driel, and J.E. Sipe: Laserinduced periodic surface structure. II. Experiments on $\mathrm{Ge}, \mathrm{Si}, \mathrm{Al}$, and brass. Phys. Rev. B 27, 1155 (1983).

9. J.F. Young, J.E. Sipe, and H.M. van Driel: Laser-induced periodic surface structure. III. Fluence regimes, the role of feedback, and details of the induced topography in germanium. Phys. Rev. B $\mathbf{3 0}$, 2001 (1984).

10. X.C. Wang, G.C. Lim, F.L. Ng, W. Liu, and S.J. Chua: Subwavelength periodic ripple formation on GaN surface by femtosecond laser pulses. Sur. Rev. Lett. 12, 651 (2005).

11. A.M. Ozkan, A.P. Malshe, T.A. Railkar, and W.D. Brown: Femtosecond laser-induced periodic structure writing on diamond crystals and microclusters. Appl. Phvs. Lett. 75, 3716 (1999).

12. N. Yasumaru, K. Miyazaki, and J. Kiuchi: Femtosecond-laserinduced nanostructure formed on hard thin films of TiN and DLC. Appl. Phys. A 76, 983 (2003).

13. Y. Lu and S.C. Chen: Nanopatterning of a silicon surface by near-field enhanced laser irradiation. Nanotechnology 14, 505 (2003).

14. B.R. Tull, J.E. Carey, E. Mazur, J.P. McDonald, and S.M. Yalisove: Silicon surface morphologies after femtosecond laser irradiation. MRS Bull. 31, 626 (2006).

15. R.L. Harzic, H. Schuck, D. Sauer, T. Anhut, I. Riemann, and
K. Konig: Sub-100 nm nanostructuring of silicon by ultrashort laser pulses. Opt. Express 13, 6651 (2005).

16. A.G. Cullis and L.T. Canham: Visible light emission due to quantum-size effects in highly porous crystalline silicon. Nature $\mathbf{3 5 3}$, 335 (1991).

17. L. Pavesi, L.D. Negro, C. Mazzoleni, G. Franzo, and F. Priolo: Optical gain in silicon nanocrystals. Nature 408, 440 (2000).

18. H. Rong, A. Liu, R. Jones, O. Cohen, D. Hak, R. Nicolaescu, A. Fang, and M. Paniccia: An all-silicon Raman laser. Nature 433. $292(2005)$.

19. B.V. Kamenev, H. Grebel, and L. Tsybeskov: Laser-induced structural modifications in nanocrystalline silicon/ amorphous silicon dioxide superlattices. Appl. Phvs. Lett. 88, 143117 (2006).

20. M.C. Rossi, S. Salvatori, F. Gualluzzi, and G. Conte: Laserinduced nanocrystalline silicon formation in a-SiO matrices. Mater. Sci. Eng., B 69-70, 299 (2000).

21. Y. Kanemitsu and S. Okamato: Photoluminescence mechanism in surface-oxidized silicon nanocrystals. Phvs. Rev. B 55, 7375 (1997).

22. F. Lacona, G. Franzo, and C. Spinella: Correlation between luminescence and structureal properties of Si nanocrystals. J. Appl. Phys. 87, 1295 (2000).

23. S.M. Prokes and W.E. Carlos: Oxygen defect center red room temperature photoluminescence from freshly etched and oxidized porous silicon. J. Appl. Phys. 78, 2671 (1995).

24. L. Khriachtchev, M. Rasanen, S. Novikov, and L. Pavesi: Systematica correlation between Raman spectra, photoluminescence intensity, and absorption coefficient of silica layers containing $\mathrm{Si}$ nanocrystals. Appl. Phys. Lett. 85, 1511 (2004).

25. S. Takeoka, M. Fjii, and S. Hayashi: Size-dependent photoluminescence from surface-oxidized $\mathrm{Si}$ nanocrystals in a weak confinement regime. Phvs. Rev. B 62, 16820 (2000).

26. D. Kovalev, H. Heckler, M. Ben-Chorin, G. Polisski, M. Schwartzkopff, and F. Koch: Breakdown of the k-conservation rule in Si nanocrystals. Phvs. Rev. Lett. 81, 2803 (1998).

27. L. Tsybeskov, K.D. Hirschman, S.P. Duttagupta, M. Zacharias, P.M. Fauchet, J.P. McCaffrey, and D.J. Lockwood: Nanocrystalline-silicon superlattice produced Appl. Phvs. Lett. 72, 43 (1998).

28. T. van Buuren, L.N. Dinh, L.L. Chase, W.J. Siekhaus, and L.J. Terminello: Changes in the electronic properties of $\mathrm{Si}$ nanocrystals as a function of particle size. Phvs. Rev. Lett. 80. 3803 (1998).

29. I.H. Campbell and P.M. Fauchet: The effects of microcrystal size and shape on the one phonon Raman spectra of crystalline semiconductors. Solid State Commun. 58, 739 (1986). 